\title{
Generative Solutions: Adaptation and Flexibilization in Housing as a Qualified Social Response
}

\author{
Ana Catarina Costa Gomes \\ ISCTE Institute University of Lisbon, and \\ VitruviusFablab-IUL, Portugal \\ anaccostagomes@gmail.com \\ - Alexandra Paio \\ ISCTE Institute University of Lisbon, \\ ISTAR-IUL and VitruviusFablab-IUL, Portugal \\ alexandra.paio@iscte.pt, vitruviusfablab@iscte.pt
}

\begin{abstract}
Housing for all is back on the international agenda. The economic crisis forces researchers and architects to rethink the concept of living and adopt more flexible housing design strategies as an alternative to typologies that impose rules of coexistence and do not reflect the social dynamics of a community.

The introduction of rules-based housing design strategies allows the implementation of more dynamic processes. This ongoing research is a reflection on the potential of digital tools to develop spatial and formal parameters based on analysis of flexible housing models. This paper presents the initial phase of the research.
\end{abstract}

Keywords: Adaptive and Evolutionary Housing, Social Dynamics, Digital Tools

\section{Introduction}

"What is Flexible Housing?

Our broad definition of flexible housing is housing that can adjust to changing needs and patterns, both social and technological. These changing needs may be personal (say an expanding family), practical (i.e. the onset of old age) or technological (i.e. the updating of old services). The changing patterns might be demographic (say the rise of the single person household), economic (i.e. the rise of the rental market) or environmental (i.e. the need to update housing to respond to climate change)" (Schneider \& Till, 2007, p.4).

In the 60s and 70s of the last century, the lack of a qualified response to housing problems in the periphery of the cities inspired alternative theories and experiences that led architecture free from the top down control logic.

That was a period of great reflection about the real needs of architecture users (Carlo, 1980). In this context, the emergency of a multidisciplinary approach from compartmental psychology to anthropology has made frequent the use of disciplines that could help to systematize the role of users or inhabitants, as well as their aspirations. Rapoport (1969) in his work "House, form and culture" gets back to the topic of creation of form and its physical, social and cultural constraints, in a predominant anthropological conception. Turner (1973) proposes a radical perspective about the housing participation subject. He suggests that housing must pass through the inhabitant control. Tuner stresses in his book "Freedom to build" that "Good housing, or the solution of housing problems (under nonemergency condition), is seen as a product of people's freedom to build" (Turner, 1972, p. 257). Thus, when the inhabitants control the main decisions and have freedom to contribute to the design, the construction and the planning of their houses, the process as well as the created environment stimulates the individual and social welfare. This author defends an important principal that housing in is not what it is but what it can do for the lif of its inhabitants. In other words, the inhabitants' satisfaction is not necessarily related to the imposition of standards (Till et al., 2005). Levebre (1981) in his book "La production de l'espace", argues that participation as an appropriation of space and creation of an identity by the users or inhabitants. Given that the inhabitant decides the spatial organization of the house. This may avoid future rejection, so many times experienced in social housing.

The replacement of inhabitant participative, incremental and adaptive side exposes a way to develop a methodology of intervention concerning social housing. Harbraken (1972) developed the "support theory" where the user is the promotor of solutions adapted to his own needs or wishes, transposing the massification of collective housing. These concepts have been explored by SAR (StichtingArchitecten Research) and Open Building (Kendall, 1999).

In Portugal, Portas drive a reflection about the question of 
habitat related to the experiences with participative housing in Peru, Brazil and Morocco (Dias \& Portas, 1972). Following the 1974, April 25th Revolution, Portas is called to be director of the Secretary of State of Housing and Urbanism on the first provisional governments and introduces an all new urban policy which, among others, rises the "Serviço de Apoio Ambulatório Local (SAAL) (Bandeirinha, 2011). Coelho (2007), in his book "Habitação Humanizada" citing Luciano Semerani (2000), addresses the importance of a humanized housing as a place of identity. Semerani (2000) refers that architecture always had the pretension to please not only the present, but what it lasts as well.

Facing the growing trend to housing design that only corresponds to a household in a specific period of time, Till and Schneider (2005) argue that a housing has to be flexible to be socially, economically and environmentally viable. According to them "(...) It includes the potential to make changes prior to occupation as well as the ability to adjust one's housing over time after occupation" (Till \& Schneider, 2005, p.4). These authors suggest that the degree of flexibility is determined in two ways: (1) space capability of different social uses; (2) space capability of different physical arrangements. Even based on these principles it is commonly recognized that flexible housing has never been totally accepted and the trend to design buildings to fit one kind of household in a specific period of time continues, reflecting a short term planning of housing. Therefore, there has been the need to think housing design in a long term period and a more deep comprehension of households' dynamics and their expectation. These have a fundamental role in the development of projects that will satisfy the present and the future users' needs.

The social, economic and technological transforms are challenging architects to investigate housing architecture. In a contemporary society where household's "families" are in constant mutation, the spatial solutions offered in the field of social housing are not answering to the demands of flexibility, personalization and inhabitant's diversity.

Therefore, there is an opportunity for a conceptual method that offers a wide range of options to the construction of housing minimum elements, as well as the possibility of a continuous construction regarding needs and possibilities of inhabitants. This means adaptive and incremental houses to families in a constant change

The technological development, along with the social and economic changes has been motivating the search for more valuable housing solutions (Botha \& Sass, 2006; Parvin, 2013; Duarte, 2007; Madrazo, 2009).

The evolution of parametric/algorithmic software associated to different ways of production is creating a new digital approach to architectural housing design (Kolarevic, 2005, Chin Ryan, 2005). According to Kolarevic (2005, p. 17) "Parametric can provide for powerful conception of architectural form by describing a range of possibilities, replacing in the process stable with variable, singularity with multiplicity. Using parameters, designers could create an infinite number of similar objects, geometric manifestations of a previously articulated schema of variable dimension, relational or operative dependencies".

The architecture is basically a prototypical activity which starts to beneficiate from the advantages of customized mass production - precision, lower costs, simulation and testing. Kieran and Timberalke (2002) argue that "we have found that mass customization offers real change for architecture and construction (...). Unlike Henry Ford, we do not imagine that "one size fits all" will work for all designs, all projects, at all sites, with all clients" (p. 135). These changes are justifying the adjustment to a new paradigm from sequential way of construction to digital fabrication building.

In this context, it is vital to understand deeply the new ways of inhabitants living based on the dynamics of domestic space appropriation, along with the digital tools that are able to emulate interrelations between planning, generation, simulation and manufacturing a range of housing solutions.

\section{Methodology to generate the social housing solutions}

In response to the lack of a qualified social housing, and to people needs and aspirations, this ongoing research intends to create a tool to generate qualified housing solutions through digital rule-based processes and implement a file-to-factory digital process.

Based on the analysis of a wide range of flexible and interactive housing design models the main aim of this study is to develop an optimized process for low cost modular housing production through the use of generative and parametric digital tools. Thus, it will be possible to meet the basic rules of diversity, flexibility and customization of the inhabitants' needs and local municipal authorities. To pursue this goal it is necessary to:

(1) Understand the contemporary social dynamics: identify households and their aspirations; measure space ownership patterns and ways of living;

(2) Define a series of logics for variable housing (size, function and evolutionary and adaptive spatial composition), based on a minimum structure, which is also flexible and incremental; and

(3) Develop a computational parametric system to explore CAD/CAM systems. This system will allow the continuous optimization of the construction processes.

\section{Social dynamics}

Society as human organization is a vehicle of tradition and culture. It is in society that people finds is communication interlocutors, share experiences, knowledge and internalize new cultures (Carneiro, 2003).

The housing architecture appears as a process of communication with others and places, as well as an identity factor. In other words, house is a complex system that guides the relationships with places, space and society (Carneiro, 2003). Several researches show that the housing 
users appropriation is not just a functional process, but an embracing of uses diversity, cultural appropriation, symbolic and affectivity (Guerra, 1997).

According to Carneiro (2003) there are three main levels of approach to examine housing appropriation: (1) an approach mainly sociological, studying the ways of life and housing appropriation. At this level, this approach has been defined around three fundamental points: (1.1) the function of housing space as a structuring ways of life; (1.2) use forms and living space appropriation; and (1.3) the residential satisfaction factors; (2) the psychological appropriation with use of structural variables of psychology. Many researchers use psychology, such as environmental psychology and transactional analysis, starting from the models analysis of use forms and housing appropriation; and (3) the symbolic appropriation, increasingly autonomous and interdisciplinary social sciences field. For the anthropologist Rapport the domestic space has various points of analysis: (1) the specialization degree of space-habitation: diverges according to social group's membership. (2) furniture distribution: where which furniture pieces are placed; (3) isolation degree of the divisions: for some people it is essential to have isolation, for others not; and (3) dividing space for social functions and hierarchy roles: different family roles generate differentiated space appropriation.

Another way to analyze people's habits is to monitoring the information in population census. As Moreira (2013) says it is a reliable way of collecting data about population, family and housing. The census data allows a better understanding of each country social changes.

For example, in Portugal, based on the census of 2011, it is possible to point up relevant information to this housing study:

\section{(1) population and territory:}

- the metropolitan areas of Lisbon and Porto keeps propensity growth in the city and suburbs;

- the population aging index decrease;

- the marriage decrease and increases singles; and

- the population living in the outskirts of large cities is increasing.

(2) family:

- the number of families and large families have decreased;

- the number of single parents is increasing;

- the proportion of single-parent households is increasing; and

- the increase of single person households made up of an elderly.

(3) housing:

- the average number of dwellings per building increases;

- increased construction trend of collective buildings;

- with regard to the building typology, there was an increase in the average number of divisions houses; and
- the house size shows that the national average is $109.9 \mathrm{~m} 2$ of floor space and $96 \mathrm{~m} 2$ to Lisbon, with an national average number of divisions area of $22.07 \mathrm{~m} 2$, and $21.01 \mathrm{~m} 2$ for Lisbon.

According to Moreira (2013) social trends should lead to a housing program reflection, adapting it to new types of family organization.

In addition to the familiar model, another important factor is the working model, which recently has been changing. For Alcalá (1995), this is a new model, contrasting the transformation of the traditional model, based on stable work and housing to nuclear family in contemporary model of unstable work, scarce and residential mobility along with the change in the family model. In Elizabeth Freire words it is notorious and relevant the "transience that dwelling is confronted in this progressive nomadism of contemporary society (...)" (Freire, p. 32).

The new labor paradigm, made possible by technological development - work from home, highlights the importance of study habits / work housing requirements to realize the adequacy of current accommodation to new employment models, allowing to infer the lack or absence of own spaces for that particular function. It is also to observe the transfer of traditionally domestic activities to the consumer society, particularly regarding food, body care, children management, leisure and entertainment (Moreira, 2013).

Understanding the social dynamics in this study, it holds on the one hand, with the understanding and assessment of needs and functional housing requirements, which needs the information provided by the census and on the other hand, the aspirations, customization and domestic space appropriation, that requires an assessment and understanding arising from the use and dependent users.

Nascimento e Oliveira claims that the architect as the major actor in the potential of the appropriation, defending spatial and functional flexibility as an essential condition so it can be emerge the appropriation, regarding that more rigid and limited the space is, the lower the possibility of appropriation.

\section{Housing minimum structure}

To Freitas, Menezes and Coelho (1996) the residential sets, and specifically the domestic sets, can be shown as transactional units because it reflects the cultural values and social standards related to personal and social identity of individuals. This is presented as fundamental contexts in analysis and comprehension of continuity and transformation processes. Thus, the change and continuity are shown as essential aspects of the transactions individual/environment, stressing important study topics "the mechanisms throughout the individuals and cultures counterbalance the continuity and the change" (Altman \& Gauvain, 1981).

Freitas, Menezes and Coelho (1996) refer that the domestic contexts (the house) reflects "the way cultures and its members have to live together and relate with common opposite dialectics, like individual needs, desires, aspirations 
and motivations versus the society demands and solicitations as a whole. The individual strength reflects the individual's attempts to be unique and distinctive - independent and free of the influence of one another. These strengths are allied to their family or primary reference group satisfaction" (Altman \& Gauvain, 1981).

The house transactional process occurs at the level of action and meanings (Altman \& Warner, 1985). It is identified three general processes that involves human, spatial and time dimensions in which individuals are connected to the house (Werner, Altman \& Oxley, 1985): Social standards and sociability relations process; utility attribution process; and appropriation, attachment and identity process. In this domestic spaces theory approach perspective emerges as fundamental to the election of the utility dimension and space appropriation, in the way that this is shown as: (1) the dimension of living and housing quality - because when congregates multiple aspects, it reflects the necessary connection between the space physical attributes, cultural practices of use and appropriation of symbolic values; and (2) a dynamic dimension - because it is susceptible of revealing the construction process and development of this connections over time (Freitas, Menezes \& Coelho, 1996).

Through the study of the each selected housing models it has been possible to conduct an evaluation of each housing typology and understand the inhabitant adaptation behaviour. Thus, it is crucial to determine minimum elements that enable the evolving control and management of the dwellings over time, either by users regarding financial resources, or by the authorities regarding materials and preventing the informal construction.

In this paper are analyzed flexible housing projects to describe incremental and adaptive aspects. The first phase of the study was the study of each housing models through a formal analysis of several aspects: typology, building system, functional and users living habits. Through this synthesis we measured the types of incremental and adaptive appropriation of housing space as well as defined a set of parameters.

This research is based on the analysis of several paradigmatic examples of evolutionary and adaptive housing from several countries - Peru, Holand, Cape Verde, Portugal, etc. - and several architects - Arq. ${ }^{\circ}$ Francisco Silva Dias, Arq. ${ }^{\circ}$ Pedro Ramanlho, Luís Ramalho e Teresa Vaz, Arq. 'James Stirling, Arq. ${ }^{\circ}$ E Esguerra, Saez, Urbaneta e Samper, Arq. ${ }^{\circ}$ S N. J. Habraken, J. T. Boekholt, A. P. Thijssen, P. J. Dinjens e J. C. Carp, Arq. ${ }^{\circ}$ A. B. Coelho e A. R. Cabrira, Arq. J. Veloso e L. Abreu.

The study of these housing typologies allowed gathering information to develop a structure of minimum elements on which housing will evolve and adapt over time.

\section{Computational parametric system}

The implementation of new rule-based design processes allows to parameterization and to simulate dynamic processes.

Thanks to the design-related technological developments, design theories and processes are undergoing re-formulation and an epistemological shift. Parametric design systems now can adapt to changing context (Woodbury 2010) under the influence of parametric languages and scripting techniques (Jabi 2013) and generative processes of design (Oxman 2006) (Oxman \& Gu, 2015).

Parametric design thinking can be defined as having three characteristics - thinking with abstraction; thinking mathematically; and thinking algorithmically (Woodbury, 2010). For Rivka Oxman and Ning Gu (2015), thinking with abstraction is a base that enables parametric design as a generative approach for producing parallel alternatives and it also enables parts of the parametric model to be reused. Thinking mathematically refers to the theorems and constructions used to define the scripting language for design representation and generation. Thinking algorithmically means that the scripting language provides functions that can add, repeat, modify or remove parts in a parametric design.

Woodbury (2010) claims that in a parametric design environment designers need a different kind of knowledge that can "predict persistent effects to understand the diversity and structure of the mathematical toolbox, and to shuttle between the intended effect and mathematical invention that models it". (Oxman \& Gu, 2015, p. 2).

There are three points who generally feature parametric design process:

(1) Designers design rules and define their logical relationships in the creation of 3D visualization models;

(2) Designers can change and modify their design at any stage; and

(3) Design alternatives can be developed in parallel in any stage.

Beyond any particular formal style or design tool, parametric design thinking is emerging as a theoretical topic (Oxman \& Gu, 2013) and a key model of digital design. With the emergence of new languages and tools, and in comparison to traditional models of the parametric, the generic formulation of a Parametric Design Schema should be formulated and explored as a comprehensive theoretical framework to support design (Oxman \& Gu, 2015).

Understanding and developing methods of programing such as parametric scripting and coding for various processbased models of digital design are providing a foundation for the characterization and conceptual definition of parametric design thinking (Oxman \& Gu, 2015).

\section{Methodology applied to a minimum element - pilot study}

The pilot study is a base to assess the house minimum elements. The input to this elements determination and the relation logics are result of this case-studies analysis (Figure 1).

\section{Case Study 1 - Malagueira, Évora}

The Duarte's work offers an essential starting point for the development of this study. This work developed a design system for mass housing customization and explores new 
technologies to improve the level of customization. The aim of this work was developing a computational framework for the provision of mass housing customization design that includes production system, providing low-cost high quality housing (Duarte, 2007). Duarte's research presents a design system that includes an interactive system via Web to explore design solutions and virtual reality and rapid prototyping techniques for viewing.

This project has a great importance with regard to theoretical and practical issues of the 20th century architecture. There have been many great architecture masters addressing the problem of low-cost mass housing, using industrialization as a means of lowering costs. Malagueira (1977-) is the center of this housing discussion, as its roots in experiments carried out in Portugal after the 1974 revolution, under the program Serviço Ambulatório de Apoio Local (SAAL). The main object of discussion was the direct participation of the future residents. The Malagueira was planned as an extension of Évora's city and includes 1200 dwellings. It was planned more than 35 different plants, from T1 to T5. Siza used a scheme based in a set of design rules to grant custom houses. However, it was difficult to pass information to other designers since this was not systematic. Thus, Pinto Duarte's research offers a technical device to explicit the Siza's design rules through the use of shape grammars It also provides a computer program encoding the grammar that allows the use of Siza's system in an effective way. It also provides computer programs associated with techniques of rapid prototyping and virtual reality to provide a computational framework for customization mass housing.

Case Study 2 - Evolutionary and Adaptive housing, LNEC. This study intended to provide technical information to support self-construction and evolutionary housing implementation processes. The author studies housing quality based on the idea that adaptability attributes and gradual inhabitant's homes improvement are key aspects for the adjustment of the houses lifestyles.

This work was selected for considering some adaptive and incremental basic conditions to housing scenario: (1) the real ability to gradually reach a stage of growth and improvement; (2) the capacity of constant adaptation in each stage of growth; (3) the adaptability to innovative environmental and physical conditions; (4) the acceptance that some operations of development reveal necessary ability; (5) the acceptance of critical periods in which is verified provisory anomalous usage ability; (6) the ability to adequate to several housing needs; (7) the housing adaptation to sites; (8) the adaptability to different social groups; and (9) initial shelter levels and urban evolution.

An adaptive and incremental modular housing solutions formulation emerges as an effective answer to the needs and aspirations of their users, through optimization of continuous construction processes. Even though it is not a new issue, it assumes a new role with the emergency of techniques and generative parametric computational methods and digital fabrication that allows a more qualified and easier to control custom mass production, with benefits both for authorities and inhabitants.

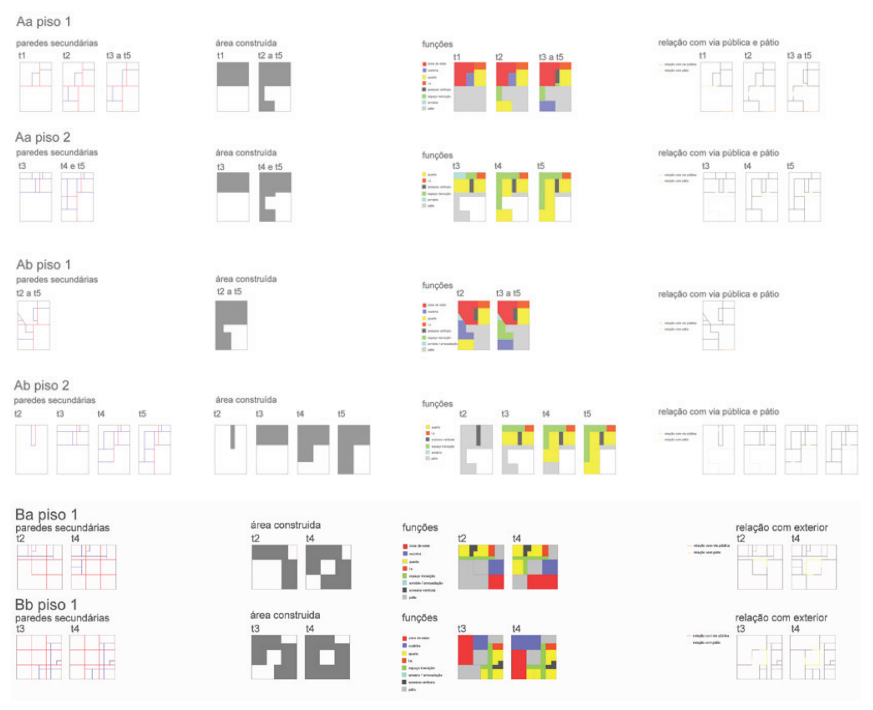

Figure 1: Case-studies analysis.

The plants of the 4 models ( 3 typological types from Bairro da Malagueira and 1 house from Vivenda Previ/Lima) where analysed and rules were extracted. We can see in figure 1 and 2 the plants of several typologies in Bairro da Malagueira and Vivenda Previ/Lima. Through the housing plan analysis it has been possible to define a range of criteria, such as: (1) main walls; (2) secondary walls; (3) constructed area; (4) functions; and (5) relation to the thoroughfare and the patio. These criteria were fundamental to determine the minimum elements in this pilot study. It enabled the lot definition, the implementation, the structure, the typology, the forms of evolution and adaptation, the forms of habitat and the relations to the thoroughfare and the patio (relation with outside).

Therefore, through this information it was possible to formalize a set of rules that contribute to the algorithm construction and the generation of several solutions of minimum elements, through the analysis of these 4 models.

These 4 models were selected to produce a synthesis that allows drawing a base for house minimum elements (room, kitchen and bathroom). Over these minimum elements it will be made the house evolution and adaptation throughout the time.

\section{Algorithm for determination of housing solutions}

This pilot study is confined to the determination of rules to the generation of minimum elements solutions. These are composed by 1 kitchen, 1 bathroom and 1 room and they are inside an allotment.

Through the development of rules created to the 4 
models, it was possible to generate 2 derivations starting from the rules application that result in a complex solutions system.

The system structure is composed in a tree shape (Figure 2). The upper level refers to a dimensional parametrization of the allotment. In the second level there are two types of possible shapes with the respective main structures. The next level regards the thoroughfare quoting the allotment. In this case it is presented only 2 solutions: east and west. The fourth level regards the solar exposure, and it is given the significance to the west side in the living area. In the level below it's possible to see the implementation of the constructed area. The sixth level refers to the functional organization of the several solutions. In the last level, through the relation with the thoroughfare and the solar exposure, it was established relations between the house entry door and the allotment entry.

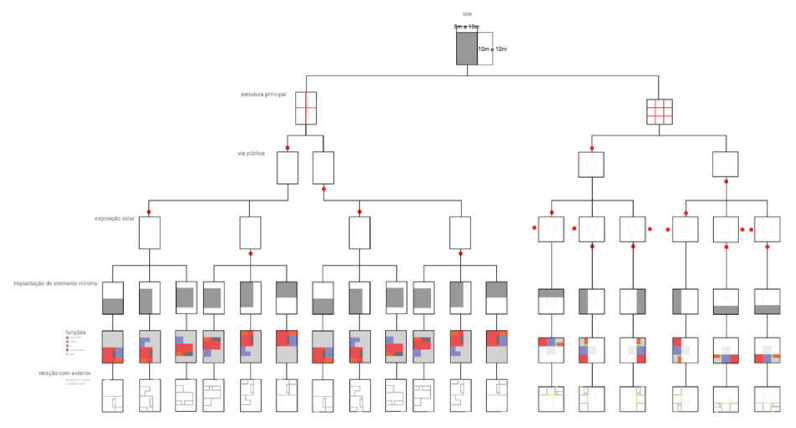

Figure 2: Generation solutions based on the case studies

\section{Conclusions}

This paper is part of a study whose goal is to develop computational system based on parametric rules to improve the production of social housing. It will allow the development of a low-cost modular housing production through the optimization of continuous construction processes that respond to a diversity of inhabitants' requirements. It is presented as a qualified response to the needs and future aspirations of its users.

In this work it was possible to determine some housing minimum elements and understand incremental and adaptive patterns. So, the algorithm construction is possible. The definition of this algorithm is presented as a dynamic growth process, which will be powered by the inclusion of new models. In next steps it will be studied more Portuguese adaptive housing projects in order to facilitate a basis for an extensive panoply of elements for the computational housing system. These elements will also improve a dynamic process among potential users in a combination that will generate a dwelling to user's needs, (cultural, social, geographical, physical and urban context).

Nevertheless, going along with the previous stages it will be determined a building system, which will be compatible with the support and types of logical formalized ownership, so that it makes possible the use of systems such as the Wikihouse (Alastair, 2013) or technologies such as highperformance Microconcrete (Campos, 2013). The building system will be seen as a way to optimize processes, in order to offer a structural and material qualified housing to users.

\section{Bibliography}

ALCALÁ, L.C., La Question Residencial: Bases Para uma Sociologia del Habitar, Fundamentos. Madrid, 1995.

ALTMAN, I., GAUVAIN, M., A cross-cultural and dialectic analysis of homes. in L.S. Liben, A.H.Patterson e N. ewcombe (Edts.), Spatial Representations and behavior across the lfe span, London: Accademic Press,1981.

AA.VV, O Processo SAAL, 2014, Museu de Arte Contemporanea de Serralves.

BANDEIRINHA, J. A., O Porcesso SAAL e a Arquitectura do 25 de Abril de 1974. Coimbra: Imprensa da Universidade, 2011.CABRITA, A. R., COELHO, A. B., Habitação evolutiva e adaptável. Lisboa: LNEC, 2009.

CAMPOS, P. E. F., Microconcreto de alto desempeño: La tecnología del microcad aplicada en la construcción del hábitat social. 1. Edição. São Paulo: Mandarim, 2013.187p.

CARNEIRO, H., Processos de Realogamento e Apropriação do Espaço num Bairro Multi-Étnico. Lisboa: Instituto Superior de Serviço Social de Lisboa, 2003. Tese de Mestrado.

COELHO, A. B., Habitação Humanizada. Lisboa: LNEC, 2007. COELHO, A. B., Habitação evolutiva e adaptável. Lisboa: LNEC, 2009.

COELHO, A. B., FREITAS, M. J., MENEZES, M., Contributos Sociológicos para a Análise e Definição de Qualidade Residencial. Sociedade Portuguesa de Sociologia, III Concresso Português de Sociologia, 1996.

CHIAN, R., How Mass Customization Changes the Design Process: MIT Media Lab's Concept Car Project MCP. Hong Kong, 2005.

DE CARLO, G., 'An Architecture of Participation', Perspecta, 17 (1980), 74-79.

DUARTE, J. P., Personalizar a Habitação em Série: Uma Gramática Discursiva para as casas da Malagueira do Siza. Lisboa: Fundação Calouste Gulbenkian. Fundação para a Ciência e Tecnologia, 2007.

FREIRE, E., 'Habitação, Sinónimo de Qualidade, Vida e Conforto Humano...'. In NEVES, Vitor - Habitar.

GRANDE, N., O Ser Urbano: Nos Caminhos de Nuno Portas. Lisboa: Imprensa Nacional - Casa da Moeda, 2012.

GUERRA, I., Um Olhar Sociológico Sobre o Alojamento. Sociologia - Problemas e Práticas, n 24, pp. 165-181. Lisboa, 1997.

HABRAKEN, N. J., Supports: an alternative to mass housing. London: Architectural Press, 1972.

JABI, W. (eds), Parametric Design for Architecture,

Laurence King, London, 2013.

JONES, P. B., PETRESCUS, D., TILL, J., Architecture and Participation. London and New York: Taylor \& Francis, 2005.

KENDALL, S., "Open Building: An Approach to Sustainable 
Architecture". Journal of Urban Technology, Volume 6, Number 3, pp 1-16, 1999.

KIERAN S., TIMBERLAKE, J., Refabricating Architectur. McGraw-Hill Professional, 2003.

KOLAREVIC, B., KLINGER, K., Manufacturing Material Effects: Rethinking Design and Making in Architecture. Routledge, 2008.

LEFEBVRE, H., La production de l'espace. Paris: Anthropos, 2000.

MADRAZO, L., COJO, A. M., SICILIA, Á., GONZÁLEZ, M., Barcode Housing System: Integrating floor plan layout generation processes within an open and collaborative system to design and build customized housing In: Joining Languages, Cultures and Visions - CAAD Futures 2009 Edited by: T. Tidafi and T. Dorta. 656- 670 Computer Aided Architectural Design Futures Montreal, Canada: Presses de l'université de Montréal (PUM).

MOREIRA, A., À Procura dos Novos Modos de Habitar. Lisboa: FAUL, 2013. Tese de Mestrado.

OLIVEIRA, Francisco Carlos Almeida do Nascimento e Os Novos Lugares do Habitar e as Formas de Apropriação Contemporâneas. Lisboa: Faculdade de Arquitectura, 2001. Tese de Mestrado.
OXMAN, R., Theory and Design in the First Digital Age, Design Studies, R. Oxman (ed.) special issue on Digital Design, 2006.

OXMAN, R, GU, N, Theories and Models of Parametric Design Thinking, Technion Israel Institute of Technology The University of Newcastle, 2015.

PARVIN, A., TED2013: Architecture for the people by the people. Acedido a 15 de Abril:

http://www.ted.com/talks/alastair_parvin_architecture_ for_the_people_by_the_people (acesso Abril 2015).

RAPOPORT, A., House Form and Culture (Foundations of Cultural Geography Series). Prentice Hall, 1969.

SASS, L, Marcel BOTHA, M., ( ) The Instant House: A Model of Design Production with DigitalFabrication, international journal of architectural computing, issue 04, volume 04, 109 $-123$.

SCHNEIDER, T., TIL, J., Flexible housing: opportunities and limits. Cambridge Journals, theory, arq. volume 9, number 2, 2005.

SILVA DIAS, F., PORTAS, N., Arquitectura, 1972. n 126.

WOODBRY, R., Elements of Parametric Design, Routledge, N.Y., 2010. 